\title{
A broadly resolved molecular phylogeny of New Zealand cheilostome bryozoans as a framework for hypotheses of morphological evolution
}

\author{
R.J.S. Orr ${ }^{\text {a, }}$, E. Di Martino ${ }^{\text {a }}$, D.P. Gordon ${ }^{b}$, M.H. Ramsfjell ${ }^{\text {a }}$, H.L. Mello ${ }^{c}$, A.M. Smith ${ }^{c}$, L. \\ H. Liow ${ }^{\text {a, } d, * *}$
}

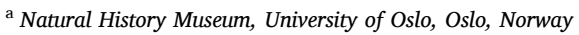

${ }^{\mathrm{b}}$ National Institute of Water and Atmospheric Research, Wellington, New Zealand

${ }^{\mathrm{c}}$ Department of Marine Science, University of Otago, Dunedin, New Zealand

${ }^{\mathrm{d}}$ Centre for Ecological and Evolutionary Synthesis, Department of Biosciences, University of Oslo, Oslo, Norway

\section{A R T I C L E I N F O}

\section{Keywords:}

High-throughput sequencing (HTS)

Genome-skimming

Cheilostome bryozoans

Phylogenetics

Frontal shield

Mitogenome

\begin{abstract}
A B S T R A C T
Larger molecular phylogenies based on ever more genes are becoming commonplace with the advent of cheaper and more streamlined sequencing and bioinformatics pipelines. However, many groups of inconspicuous but no less evolutionarily or ecologically important marine invertebrates are still neglected in the quest for understanding species- and higher-level phylogenetic relationships. Here, we alleviate this issue by presenting the molecular sequences of 165 cheilostome bryozoan species from New Zealand waters. New Zealand is our geographic region of choice as its cheilostome fauna is taxonomically, functionally and ecologically diverse, and better characterized than many other such faunas in the world. Using this most taxonomically broadly-sampled and statistically-supported cheilostome phylogeny comprising 214 species, when including previously published sequences, and 17 genes ( 2 nuclear and 15 mitochondrial) we tested several existing systematic hypotheses based solely on morphological observations. We find that lower taxonomic level hypotheses (species and genera) are robust while our inferred trees did not reflect current higher-level systematics (family and above), illustrating a general need for the rethinking of current hypotheses. To illustrate the utility of our new phylogeny, we reconstruct the evolutionary history of frontal shields (i.e., a calcified body-wall layer in ascus-bearing cheilostomes) and ask if its presence has any bearing on the diversification rates of cheilostomes.
\end{abstract}

\section{Introduction}

Large and broadly-sampled phylogenies are vital to robustly answering many different classes of evolutionary questions, including those involving trait evolution, origins and evolution of biogeographic distributions and rates of taxonomic diversification. While megaphylogenies with hundreds to thousands of species (Smith et al., 2009) are available for many groups of vertebrates (Meredith et al., 2011; Prum et al., 2015) and plants (Zanne et al., 2014), and also for some nonvertebrate terrestrial groups (Varga et al., 2019), the molecular phylogenetics of many marine invertebrate groups remains relatively neglected (Arrigoni et al., 2017; Kocot et al., 2018; O'Hara et al., 2017).

In this contribution, we begin to rectify the paucity of large and/or taxonomically broadly sampled molecular phylogenies for marine invertebrates, targeting a phylum whose rich fossil record can be subsequently integrated for evolutionary analyses. Our focal group is
Cheilostomatida, the dominant living order of the colonial metazoan phylum Bryozoa, with c. 5200 described extant species, corresponding to $>80 \%$ of the living species diversity of the phylum (Bock and Gordon, 2013). Cheilostomes first appeared in the fossil record in the Late Jurassic (c. 160 million years ago) and then displayed a spectacular diversification c. 55 million years later in the mid-Cretaceous (Taylor, 2020). Cheilostomes, common in benthic marine habitats globally, are lightly- to heavily-calcified and largely sessile as adults. Most species are encrusting, while fewer are erect, with some forming robust structures whereas many are small and inconspicuous (Fig. 1). Although a number of cheilostome bryozoans have been sequenced and placed in a molecular phylogenetic context (Fuchs et al., 2009; Knight et al., 2011; Orr et al., 2019a; Waeschenbach et al., 2012) the systematics of cheilostome bryozoans aimed at reflecting their evolutionary relationships still remain largely based on morphological characters (Bock and Gordon, 2013; Martha et al., 2020; Taylor and Waeschenbach, 2015). This is in

\footnotetext{
* Corresponding authors.

E-mail addresses: russell_orr@hotmail.com (R.J.S. Orr), 1.h.liow@nhm.uio.no (L.H. Liow).
} 
part because assumed cheilostome phylogenetic relationships have only recently benefited from high-throughput sequencing (HTS) techniques and the increased phylogenetic support it provides (Orr et al., 2019a, b, 2020). HTS yields more sequence data with lesser effort compared with traditional PCR and Sanger sequencing techniques (Fuchs et al., 2009; Knight et al., 2011; Waeschenbach et al., 2012). By applying genomeskimming approaches to greatly expand on the taxonomic sampling of cheilostomes for molecular phylogenetics, we independently test phylogenetic hypotheses implicit in their current systematics (Bock, 2020), and also facilitate future studies.

We focus our sequencing effort in this contribution primarily on New Zealand cheilostomes for a number of reasons. Cheilostomes play a conspicuous role as habitat-building organisms in New Zealand as well as other temperate areas (Cook et al., 2018; Wood et al., 2012). In fact, some cheilostome thicket communities (Fig. 1A) are protected in New Zealand because of their function as nurseries for commercial fish stocks (Bradstock and Gordon, 1983). As important components of marine communities, cheilostomes are crucial members of the marine food chain globally. This is because, like all bryozoans, they are efficient suspension-feeders (Gordon et al., 1987) while also providing food for other organismal groups (Lidgard, 2008). Cheilostomes are highly diverse in New Zealand, thanks to a combination of factors, including New Zealand's geological and hydrographic setting, constituting the major part of the geological continent of Zealandia, which is 94\% submerged (Campbell and Mortimer, 2014). Additionally, the New Zealand Exclusive Economic Zone, plus its extended continental shelf, is one of the largest in the world ( 5.7 million $\mathrm{km}^{2}$ ) with a wide latitudinal spread from subtropical to subantarctic (c. $23^{\circ}-57.5^{\circ} \mathrm{S}$ ). It also has varied seafloor topography, including extensive deep shelves, plateaus, ridges and seamounts (Gordon et al., 2010). Within this area, New Zealand has 359 genera and 1053 species of marine Bryozoa, including 867 cheilostomes (of which 285 species remain to be formally described). About $61 \%$ of New Zealand's marine Bryozoa are endemic (Gordon et al., 2019), making New Zealand a doubtless diversity hotspot for cheilostome bryozoans. Complementing Recent diversity, the published Cenozoic record of cheilostome bryozoans is also rich, though relatively less studied (Brown, 1952; Gordon and Taylor, 2015; Rust and Gordon, 2011), comprising 531 species (of which 240 are in open nomenclature). This complementarity of living and fossil species renders a molecular phylogeny of New Zealand taxa amenable to modern statistical methods that integrate molecular and fossil data for inferring evolutionary processes (Heath et al., 2014). Last, but not least, New Zealand is one of the better-studied marine regions taxonomically and ecologically for Bryozoa (e.g. Gordon, 1984; 1986; 1989; Gordon et al., 2009; Schack et al., 2020), a phylum that is somewhat neglected in many other parts of the world. Bryozoan research has been continuously conducted in New Zealand since 1841 (Gordon et al., 2009) and a governmental agency, the National Institute of Water and Atmospheric Research (NIWA), is both the data manager and custodian for fisheries and invertebrate research data, hence assuring knowledge curation. All of this means that a cheilostome phylogeny with New Zealand species broadly represented allows us to begin to ask evolutionary and ecological questions while controlling for phylogenetic non-independence.

Here we apply a genome-skimming approach to New Zealand cheilostome bryozoans and present a robustly supported molecular phylogeny based on 15 mitochondrial and 2 rRNA genes. The molecular

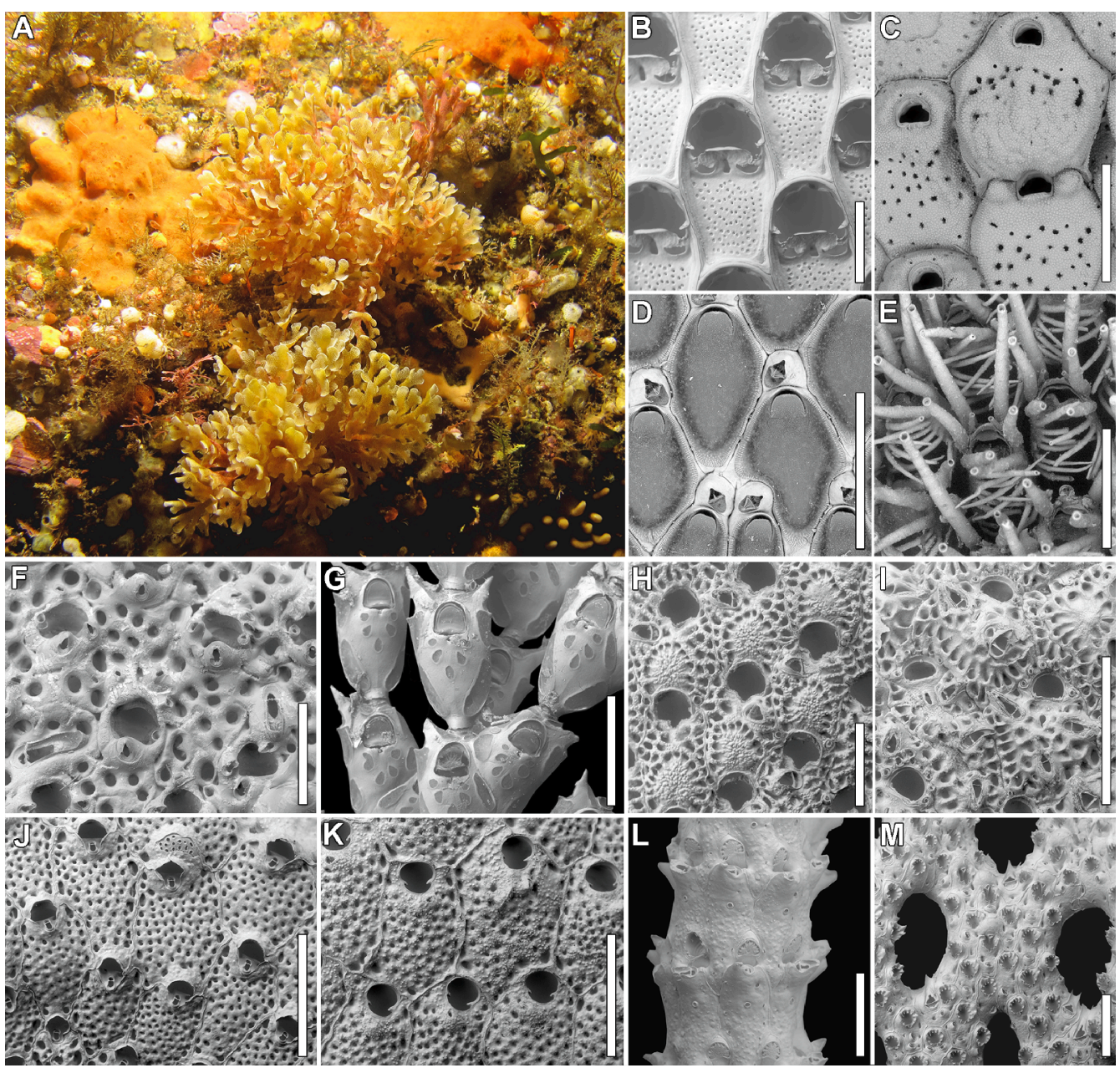

Fig. 1. New Zealand Bryozoans. (A) Foliose branching colonies of the cheilostome bryozoan Euthyroides episcopalis from Fiordland, New Zealand (photo by Dr Mike Page, NIWA). (B-M) Scanning electron micrographs of various New Zealand cheilostome bryozoans (B-E: anascan-grade; F-M: ascophoran-grade). (B) Steginoporella perplexa (Steginoporellidae; BLEED 1651). (C) Monoporella $\mathrm{n}$. sp. (Monoporellidae; BLEED 1360). (D) Ellisina sericea (Ellisinidae; BLEED 697). (E) Beania stonycha (Beaniidae; BLEED 84). (F) Arachnopusia unicornis (Arachnopusiidae; BLEED 221). (G) Orthoscuticella fusiformis (Catenicellidae; BLEED 1623). (H) Chiastosella watersi (Escharinidae; BLEED 56). (I) Calloporina angustipora (Microporellidae; BLEED 793). (J) Smittina rosacea (Smittinidae; BLEED 1700). (K) Bitectipora cincta (Bitectiporidae; BLEED 801). (L) Galeopsis n. sp. 2 (Celleporidae; BLEED 1618). (M) Iodictyum yaldwynii (Phidoloporidae; BLEED 1387). All scale bars are $0.5 \mathrm{~mm}$. 
sequences of 199 cheilostome colonies sampled in New Zealand are presented here for the first time. Using 180 species and 96 genera from New Zealand and previously sequenced, non-New Zealand species, we construct the largest and most taxonomically broadly sampled cheilostome phylogeny to date, with 263 in-group colonies, representing 214 species and 120 genera. The inclusion of non-New Zealand taxa allows us to explore the robustness of the inferred relationships among New Zealand species but also reduces phylogenetic inference errors by nature of a broader taxonomic sampling (Pollock et al., 2002). To illustrate the utility of our inferred tree for understanding cheilostome evolution, we reconstruct the evolutionary history of a morphological trait (the frontal shield), where it is thought that there have been repeated gains, and perhaps losses, of a calcified (ascophoran) shield (Gordon, 2000). The state of the frontal shield is crucial for the mechanics of extrusion of the feeding tentacles (lophophore) and the protection of the retracted polypide (the soft tissue of the bryozoan) (Taylor, 2020). To demonstrate our inferred tree's utility, we also ask if the diversification (i.e. speciation and extinction) rates of cheilostomes that have such a shield (ascophoran-grade; Fig. 1F-M) are different from those that do not (anascan-grade; Fig. 1B-E). We also discuss several other key taxonomic traits, including the presence of a frontal shield opening (ascopore; Fig. 1I), widely thought to be evolutionarily stable and the consequences our highly resolved cheilostome phylogeny has for these. Our contribution is a first step towards a global cheilostome megaphylogeny, needed for answering biological questions that go beyond those probing genealogical relationships.

\section{Methods}

\subsection{Sampling \& SEM}

Sequences are provided here for 207 New Zealand cheilostome colonies that were collected during several field expeditions by NIWA and University of Otago, New Zealand. While we have newly sequenced 199 colonies, we also supply unpublished sequences for 8 extra colonies we previously presented (see Supplementary Table S2). Samples were sorted, preserved in $70-96 \%$ ethanol, then shipped to the University of Oslo, Norway, for processing. Each bryozoan colony, preliminarily identified to the lowest possible taxonomic level (usually genus but sometimes species) using a stereoscope, was subsampled for DNA isolation, and also for scanning electron microscopy. The scanning electron micrographs (SEMs), taken with a Hitachi TM4040PLus after bleaching to remove tissue (where appropriate), are required for species-level confirmation. All SEM digital vouchers are supplied as a supplementary data file. Taxonomic identifications are made independently of the phylogenetic inference and metadata to avoid identification bias.

\subsection{DNA isolation, sequencing and assembly}

The 199 subsamples of colonies (henceforth "samples") were dried before genomic DNA isolation using the DNeasy Blood and Tissue kit (QIAGEN, Germantown, MD, USA). Samples were homogenized in lysis buffer, using a pestle, in the presence of proteinase-K. Genomic DNA were sequenced at the Norwegian Sequencing Centre (Oslo, Norway) using Illumina HiSeq4000 150 bp paired-end (PE) sequencing with a 350 bp insert size. Approximately 20 samples (library preps) were genome-skimmed (multiplexed) on a single lane. Illumina HiSeq reads were quality checked using FastQC v.0.11.8 (Andrews, 2010), then quality- and adapter-trimmed using TrimGalore v0.4.4 with a Phred score cutoff of 30 (Krueger, 2015). Trimmed reads were de novo assembled with SPAdes 3.13 (Bankevich et al., 2012) using k-mers of 21, $33,55,77,99$ and 127. The mitogenome and rRNA operon of each sample were identified separately with blastn (Altschul et al., 1990) using blast + against a database constructed from broadly sampled cheilostome sequences already deposited in NCBI (Orr et al., 2020). An
E-value of $1.00 \mathrm{e}-185$ and maximum target sequence of 1 were used to filter any blast hits of non-cheilostome origin.

\subsection{Annotation}

Mitogenomes for each of the samples were annotated with Mitos2 using a metazoan reference (RefSeq 89) and the invertebrate genetic code (Bernt et al., 2013) to identify two rRNA genes (rrnL and rrnS) and 13 protein coding genes (atp6, atp8, cox1, cox2, cox3, cob, nad1, nad2, nad3, nad4, nad4l, nad5, and nad6). In addition, two nuclear rRNA operon genes (ssu/18 s and lsu/28) were identified and annotated using RNAmmer (Lagesen et al., 2007). The internal transcribed spacer regions (ITS1 and 2) and the 5.8 s rRNA were not utilized in this study. Thirty published (Orr et al., 2019a, b, 2020) New Zealand samples were included in the subsequent workflow to bring the total number to 229 (Supplementary Table S2). Further, the mitogenomes and rRNA operons of 38 non-New Zealand bryozoans (Orr et al., 2020), were aligned with our samples to compile a broader cheilostome ingroup and ctenostome outgroup taxon sample.

\subsection{Aligning}

MAFFT (Katoh and Standley, 2013) was used for alignment with default parameters: for the four rRNA genes (nucleotide) the Q-INS-i model, considering secondary RNA structure, was utilized; for the 13 protein-coding genes, in amino acid format, the G-INS-I model was used. The 17 separate alignments were edited manually using Mesquite v3.61 to remove any uncertain characters (Maddison and Maddison, 2017). Ambiguously aligned characters were removed from each alignment using Gblocks (Talavera and Castresana, 2007) with least stringent parameters. The single-gene alignments were concatenated to a supermatrix using the catfasta2phyml perl script (Nylander, 2010). The alignments (both masked and unmasked) are available through Dryad (https://doi.org/10.5061/dryad.7pvmcvdrs)

\subsection{Phylogenetic reconstruction}

Maximum likelihood (ML) phylogenetic analyses were carried out for each single gene alignment using the "AUTO" parameter in RAxML v8.0.26 (Stamatakis, 2006) to establish the evolutionary model with the best fit. The general time reversible (GTR $+\mathrm{G})$ was the preferred model for the four rRNA genes ( $18 \mathrm{~s}, 28 \mathrm{~s}$, rrnS and rrnL), and MtZoa $+\mathrm{G}$ for all 13 protein coding genes. The two concatenated datasets ("New Zealand" and "global" = New Zealand + non-New Zealand, see section above), divided into 17 separate rRNA and protein gene partitions each with its own distinct gamma distribution to accommodate for different substitution patterns among sites, were analyzed using RAxML. The topology with the highest likelihood score of 100 heuristic searches was chosen. Bootstrap values were calculated from 500 pseudo-replicates.

Bayesian inference (BI) was performed using a modified version of MrBayes incorporating the MtZoa evolutionary model (Huelsenbeck and Ronquist, 2001; Tanabe, 2016). The datasets were executed, as before, with 17 separate rRNA and protein gene partitions under their distinct gamma distributions. Two independent runs, each with three heated and one cold Markov Chain Monte Carlo (MCMC) chain, were initiated from a random starting tree. The MCMC chains were run for 20,000,000 generations with trees sampled every 1,000 th generation. The posterior probabilities and mean marginal likelihood values of the trees were calculated after the burnin phase $(5,000,000$ generations). The average standard deviation of split frequencies between the two runs was $<0.01$, indicating convergence of the MCMC chains.

Congruence between the topological signal of the bryozoan nuclear rRNA operon (Supplementary Fig. S7) and mitogenome (Supplementary Fig. S8) was tested, to support their concatenation, using the Icong index (de Vienne et al., 2007). As the Icong index is dependent on identical leaves between topologies the analysis was performed on a subset (218 
of 267) where only taxa present in both the nuclear rRNA and mitogenome datasets, with $<70 \%$ missing characters for each alignment, were represented (see Table S4 and available through Dryad).

\subsection{Ancestral state reconstruction and BiSSE analyses}

The tips states of whether the sampled species is anascan $(0$, having a non-calcified frontal membrane; e.g. Fig. 1D) or ascophoran (1, having a calcified frontal shield; e.g. Fig. 1K), both states decipherable from SEMs, is given in Fig. 3. We use a standard Markov model of binary character evolution (Pagel, 1994) implemented in ape (Paradis and Schliep, 2018) to estimate the ancestral states of the nodes on our inferred phylogeny. We use a standard binary state speciation and extinction model, also termed BiSSE (Maddison et al., 2007) implemented in diversitree (FitzJohn, 2012) to investigate any differences in diversification rates due to the anascan or ascophoran frontal shield state of the species involved. As input for this latter analysis, we estimate that of the 1876 anascans and 3358 ascophoran species in Bock (2020), we have sampled $4.4 \%$ and $3.9 \%$ respectively to account for biases due to the sampling of species given the trait. We perform ancestral state

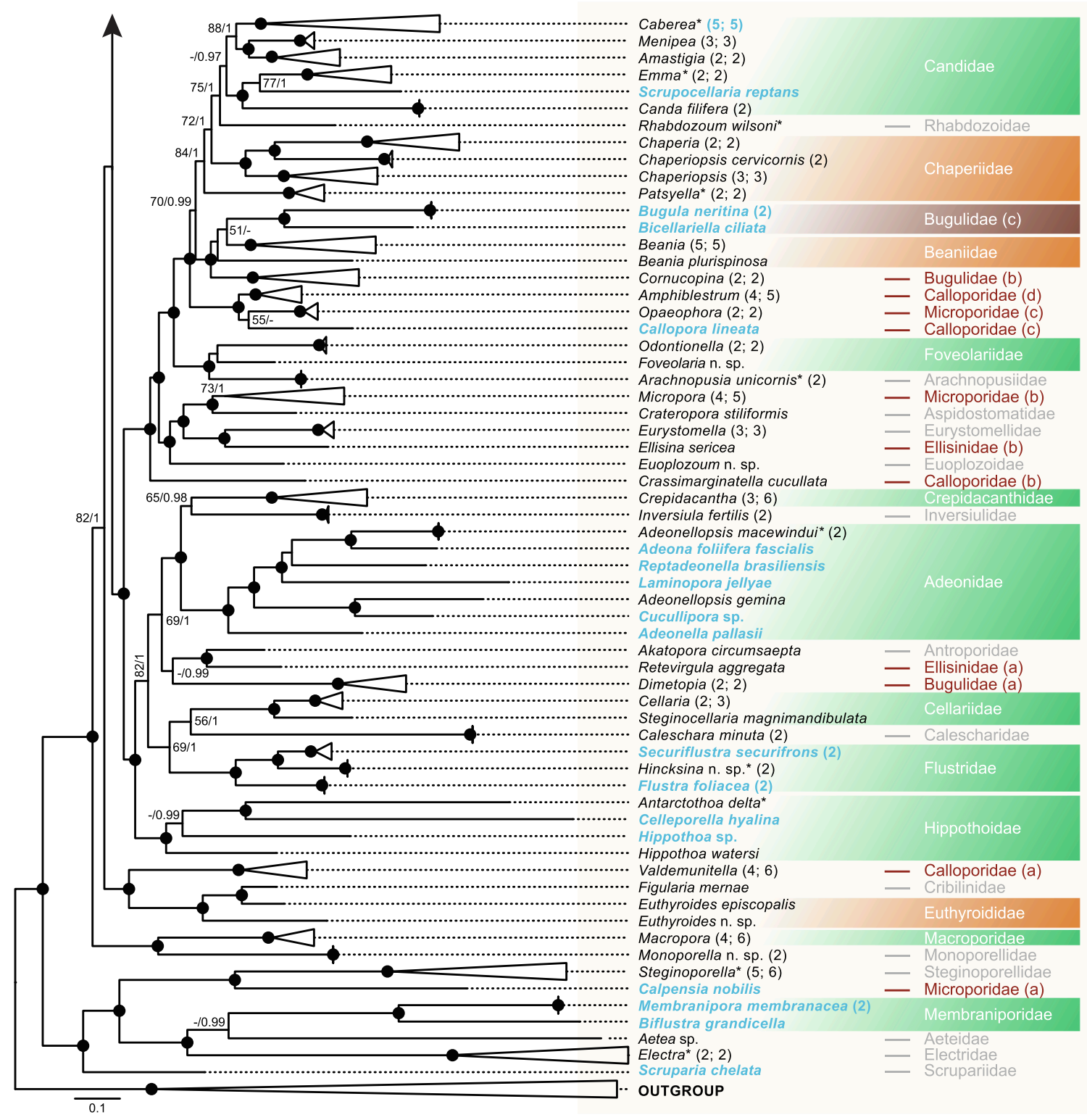

Fig. 2. The inferred phylogeny of cheilostomes based on 17 genes including New Zealand and non-New Zealand data. Maximum likelihood topology of 263 cheilostome ingroup taxa and 4 ctenostome outgroup taxa with 9493 nucleotide and amino acid characters inferred using RAxML (100 heuristic searches and bootstrap of 500 pseudoreplicates). The tree branching has been collapsed at the genus level. The numbers on the internal nodes are ML bootstrap values (BS from RAxML) followed by posterior probabilities (PP from MrBayes). Circles indicate nodes $>90$ BP and 0.99PP, BS $>50$ and PP $>0.95$ are shown in numbers and others left out. Blue text are non-New Zealand taxa, none of which were generated in this study (see Supplementary Table S2). Blue numbers dictate a collapsed genus that contains a mix of New Zealand and non-New Zealand taxa. Numbers in parentheses after branches show genus or species number followed by the number of species or colonies within the collapsed branch. * indicates taxa with sequence data generated from other studies but are also from New Zealand (see Supplementary Table S2). A green box highlights a monophyletic family (2 or more genera or in the case of monogeneric families, two or more species), an orange box a paraphyletic family, and a brown box, or brown family names, a polyphyletic family. The letter in brackets behind polyphyletic family names highlights the sub-clade. Grey family names indicate there are limited data to conclude any phylogenetic relationship (ancestry). i.e., families where only a single genus is represented, or monogeneric families where only a single species is represented. The tree is divided into two pages for ease of presentation; a) representing the basal groupings and b) the terminal groupings. (For interpretation of the references to colour in this figure legend, the reader is referred to the web version of this article.) 


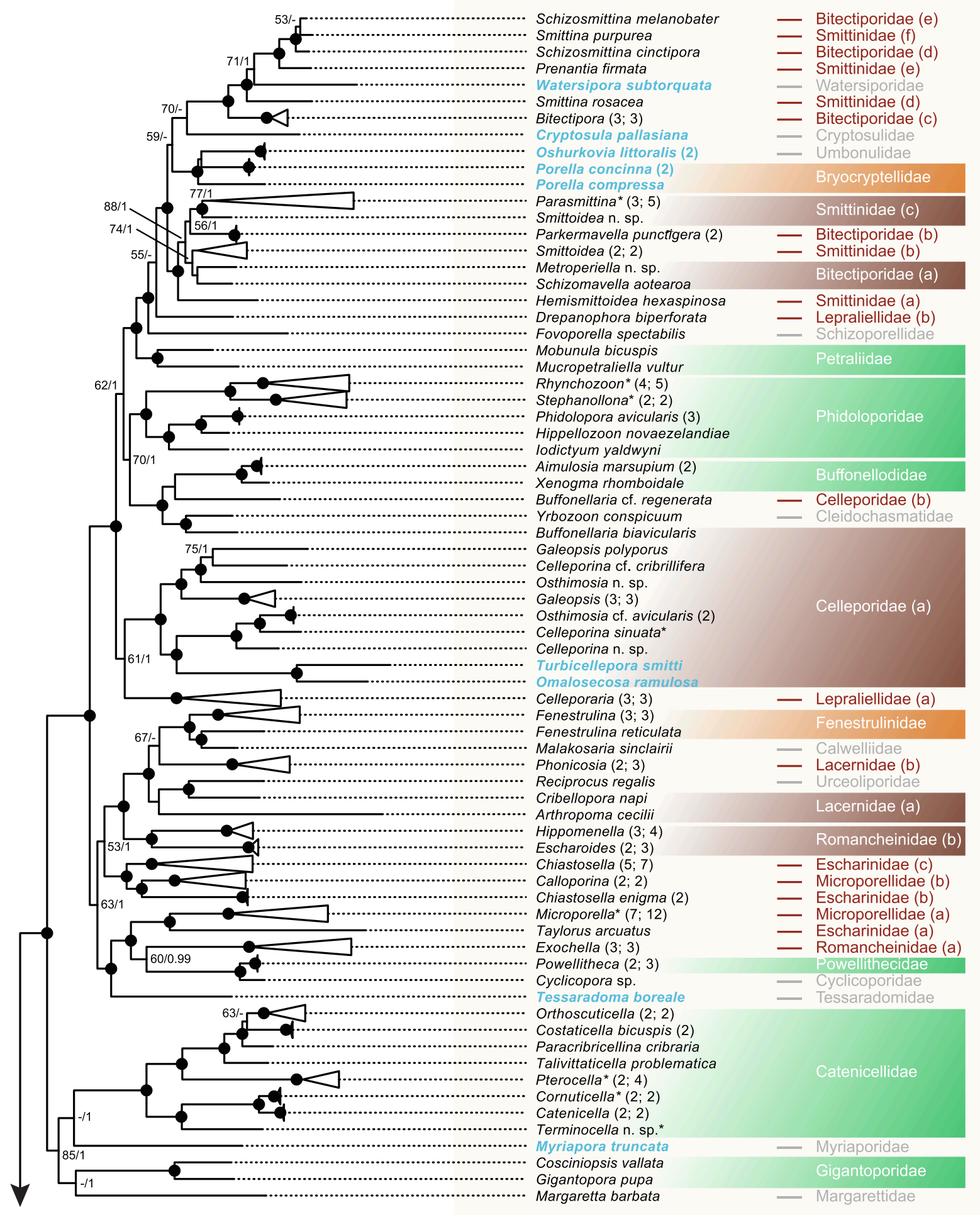

Fig. 2. (continued).

reconstruction and BiSSE analyses for both ML and Bayesian "global" trees (Supplementary Figs. S3 and S4 respectively) to account for minor differences in the topological signal (see Results) and present posterior distributions of estimated speciation $(\lambda)$ and extinction $(\mu)$ rates given an anascan (0) or ascophoran (1) state, as well transition $(q)$ rates between the two states. Note that as we do not (fossil) calibrate the branch lengths (average number of substitutions per site over the alignment) to absolute time, the estimated rates from the BiSSE will be presented in units of substitutions. In cases where there are multiple representatives within a species, we choose the colony with the highest number of nucleotides/amino-acids/genes to represent the species for these analyses.

\section{Results}

\subsection{Sequencing and concatenation}

We successfully sequenced and assembled 199 New Zealand 
cheilostome colonies, representing 165 species (SEM vouchers in Supplementary file) that have never been presented previously (Supplementary Table S1). We supply additional sequence data for a further eight species previously presented (Supplementary Table S2 and Orr et al., 2019b). The final 17 gene and 267 taxa "global" supermatrix constitutes $77 \%$ total character completeness for the dataset used to infer Fig. 2. For the convenience of future workers interested in only the New Zealand taxa, we supply also trees based on these data (Supplementary Figs. S1 (ML) and S2 (Bayesian), where character completeness is $78 \%$ ). The assembled rRNA and mitogenomes are deposited at NCBI with accession numbers (Supplementary Table S2).

\subsection{A global cheilostome phylogeny}

\subsubsection{Broad taxon-sampling}

Our inferred "global" cheilostome phylogeny, encompassing 214 species and 120 genera, from 56 families (Fig. 2) of which 229 colonies, 186 species and 96 genera, currently distributed in 48 families, are from New Zealand (Supplementary Figs. S1 and S2). The New Zealand and global trees represent c. $21 \%$ described species of cheilostomes from New Zealand and c. $15 \%$ of the described cheilostome genera globally, respectively. Both phylogenies (Fig. 2 and Supplementary Fig. S1) are robustly resolved with most branches (146 of 195 branches, or approximately $75 \%$ based on Fig. 2) receiving either high ( $>90$ bootstrap (BS)/>0.99 Posterior Probability (PP)) or full support (100 BS / 1 $\mathrm{PP}$ ). Our ingroup cheilostome taxa form a fully supported monophyletic clade, when we infer the global tree including a ctenostome outgroup (Fig. 2).

We summarize only general ingroup observations while referring the reader to topological details in Fig. 2 and Supplementary Fig. S3 that are not discussed here or in the Discussion. We also refrain from summarizing results above the family-level for reasons stated in the Discussion.

\subsubsection{Family relationships}

Several families for which we have three or more genera represented form supported monophylies (Fig. 2), e.g. the fully supported Catenicellidae (Orthoscuticella, Costaticella, Paracribricellina, Talivittaticella, Pterocella, Catenicella, Cornuticella and Terminocella; Fig. 1G), Adeonidae (Adeonellopsis, Adeona, Reptadeonella, Laminopora, Cucullipora, Adeonella), Flustridae (Flustra, Hincksina, Securiflustra), Hippothoidae (Celleporella, Hippothoa, Antarctothoa) and Phidoloporidae (Iodictyum, Hippellozoon, Phidolopora, Stephanollona, Rhynchozoon; Fig. 1M). The monophyly of the Candidae (Menipea, Amastigia, Caberea, Canda, Emma) conversely, receives poor support (-/0.97).

Of the 29 nominal families represented by two or more genera in our phylogeny, only 12 (c. 41\%) are monophyletic in our inference (Fig. 2 green boxes). Families such as the Microporidae (Micropora, Opaeophora, Calpensia), Calloporidae (Valdemunitella, Crassimarginatella, Callopora, Amphiblestrum), Bugulidae (Dimetopia, Bugula), Romancheinidae (Hippomenella, Escharoides and Exochella), and Microporellidae (Microporella, Calloporina), all currently accepted in Bock (2020), are recovered as polyphyletic with high support (Fig. 2 brown boxes), while others such as Euthyroididae are paraphyletic (Fig. 2, orange boxes). Monogeneric families (e.g. Crepidacanthidae, Macroporidae and Powellithecidae) recovered as fully supported monophylies comprising multiple species are not considered here.

\subsubsection{Genus relationships}

In contrast to family-level systematics, the 50 currently morphologically defined nominal genera for which we have two or more representatives in general (approximately 70\%) form monophyletic groupings (e.g. Parasmittina, Bitectipora, Rhynchozoon, Microporella, Amphiblestrum, Micropora, Steginoporella and 27 others) with either high or full support. A few genera are non-monophyletic (approximately $30 \%$ of those for which we have at least two representatives): several are recovered as paraphyletic in our tree (Chiastosella, Fenestrulina,
Smittoidea, Schizosmittina, Chaperiopsis and Valdemunitella), while only a handful are polyphyletic (Celleporina, Galeopsis and Osthimosia).

Because there are indications that some species are phenotypically highly variable and others have morphologies that are not yet wellunderstood, we also sequenced multiple colonies of the same species in several cases even though our goal was to sequence one colony of each species. Morphologically identified species match genetic species inferred by phylogenetic inferences in these cases, including, Parkermavella punctigera (98.86\% id over $15078 \mathrm{bp})$, Chiastosella longaevitas (99.56\% id over 15142 bp), C. enigma (99.85\% id over 14403 bp), Microporella agonistes ( $99.85 \%$ id over $14303 \mathrm{bp}$ ) and M. intermedia (99.62\% id over 13938 bp). We note that while our three Parasmittina aotea samples form a monophyletic clade, there is somewhat greater genetic variability than the species mentioned above $(86.91 \%$ id over 14236 bp). For more details, please see individual SEM cards in the Supplementary data file.

\subsubsection{Congruent trees and a single incongruent branch}

We show the inferred global nuclear rRNA (Supplementary Figs. S7 and S9) and mitogenome trees (Supplementary Figs. S8 and S10) to be topologically more congruent than expected by chance $\left(I_{\text {cong }}\right.$ index $=$ 3.77; probability that they are topologically unrelated $=6.54 \mathrm{e}-36$ ). The result supports the concatenation of rRNA and mitogenome data in cheilostome bryozoans, as previously demonstrated (Orr et al., 2019a), albeit on a smaller dataset.

For the concatenated nuclear rRNA and mitogenome datasets, we highlight the incongruent placement of the Euthyroides, Figularia and Valdemunitella clade between the ML and Bayesian trees. Note that this clade is highly supported as a monophyly in both sets of trees, but its placement within the trees is contested; the ML trees, whether based only on the New Zealand taxa or all taxa (Fig. 2, Supplementary Figs. S1 and S3), place this clade in a basal position with an affinity to the Macropora/Monoporella grouping. The Bayes trees, however, infer a more derived position. In all instances (ML and Bayes), support for the inferred placement is lacking.

\subsection{Ancestral state reconstruction and BiSSE}

A different rates model for the transition of the anascan to ascophoran state has a less negative log-likelihood (-29.24) than that for an equal rates model (-35.16), suggesting that it describes our ML tree better. Parameter estimates indicate that the ascophoran state never goes to anascan, and anascan state goes to ascophoran at rate of 0.207 (std err 0.0273), in our ML tree. The estimated node states are shown in Fig. 3. Plots of posterior distributions of speciation and extinction rates (in terms of average number of substitutions) given the frontal shield trait show a substantial overlap (Fig. 4) where the means of each group (anascan or ascophoran) are encompassed in the 95\% CI (Credibility Intervals in parenthesis) of the other group in each comparison: $\lambda_{\text {anascan }}$ $=17.74(13.15,26.05) ; \lambda_{\text {ascophoran }}=15.32(9.43,29.62), \mu_{\text {anascan }}=$ 12.57 (7.51, 21.56); $\mu_{\text {ascophoran }}=8.48$ (1.39, 24.23). However, the transition rates of the states are non-overlapping in their $95 \%$ CI: $q_{01}$ (anascan to ascophoran) $=0.19(0.08,0.42), q_{10}$ (ascophoran to anascan) $=0.03$ $(0.00,0.11)$. If we assume that cheilostomes originated in the Late Jurassic approximately 160 million years ago (Taylor and Waeschenbach, 2015), then $\lambda_{\text {anascan }}=0.12, \lambda_{\text {ascophoran }}=0.10, \mu_{\text {anascan }}=$ $0.08, \mu_{\text {ascophoran }}=0.06$ (in units of million years). Note that BiSSE is prone to type II errors (Rabosky and Goldberg, 2015) but that we actually cannot soundly reject the null hypothesis, given the posterior speciation and extinction rate distributions and are hence on safe ground. Ancestral state reconstruction for the frontal shield states and BiSSE analyses for the alternative Bayesian tree (Supplementary Figs. S5 and S6) are highly comparable with that estimates from the ML tree (Figs. 3 and 4). 


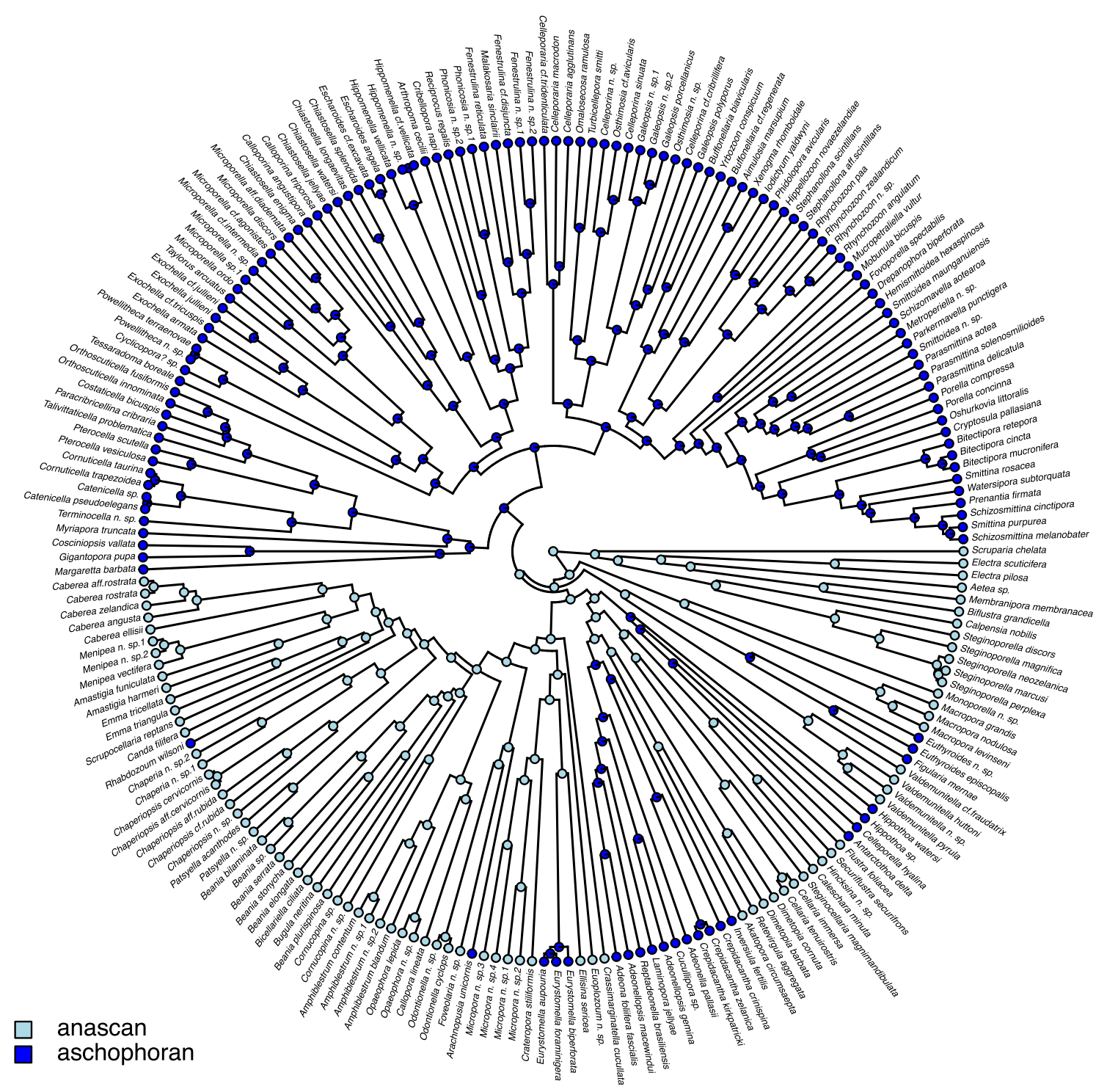

Fig. 3. Inferred frontal shield states. Ancestral state reconstruction of anascan (non-calcified frontal membrane; light blue) versus ascophoran (calcified frontal shield; blue) frontal shield states on the inferred global ML tree (see Supplementary Fig. S5 for the version based on the Bayesian tree). (For interpretation of the references to colour in this figure legend, the reader is referred to the web version of this article.)

\section{Discussion}

It has long been known that molecular and morphological approaches (the latter including fossil taxa) must be simultaneously embraced for robust phylogenetic inferences (Pyron, 2015). In this contribution, we have taken a substantial step in contributing new molecular data and a greatly expanded and robustly supported phylogeny for an understudied but ecologically and evolutionarily important phylum (Pagès-Escolà and Costello, 2020). Although we are interested primarily in New Zealand cheilostome bryozoans for reasons stated in our introduction, we have also now filled out numerous previously unsampled parts of the global cheilostome tree (compare Orr et al., 2020 with Fig. 2).

\subsection{Higher-level cheilostome systematics needs revision}

Cheilostome systematics is in a state of flux as molecular studies, coupled with the introduction of genome-skimming, are starting to take off for this diverse clade (Orr et al., 2019a, b, 2020). In providing a broadly sampled and robustly supported framework to evaluate evolutionary hypotheses we find that less than half of the 29 currently recognized families for which we have multiple genera represented are phylogenetically coherent. Our result emphasizes that much of the current family and higher-level bryozoan systematics, based largely on morphology, is unreliable, and further corroborates previous studies with statistically well-supported, but less broadly sampled, phylogenies (Orr et al., 2019a, b, 2020). One implication of this observation is that higher-level systematics (involving families, superfamilies and suborders) likely require substantial revision. We have hence refrained from detailing the mismatches of higher-level systematics (Bock, 2020) prematurely, but highlight new evolutionary hypotheses that have emerged, that are potentially supportable by morphological traits, given our molecular inferences (Fig. 2, Supplementary Figs. S3 and S4).

Notwithstanding some discrepancies between morphology-based hypotheses (Bock, 2020) and molecular data (this study), there is frequently mutual support. Take, for example, the basal grouping of Scrupariidae (Scruparia) as sister taxa to Electridae (Electra), Membraniporidae (Biflustra and Membranipora) and Aeteidae (Aetea) plus Steginoporellidae (Steginoporella) and Calpensiidae (Calpensia) (Fig. 2): these families are understood to have acquired different reproduction patterns (non-brooding in Membraniporidae and Electridae; different modes of embryonic incubation in the remaining families) 

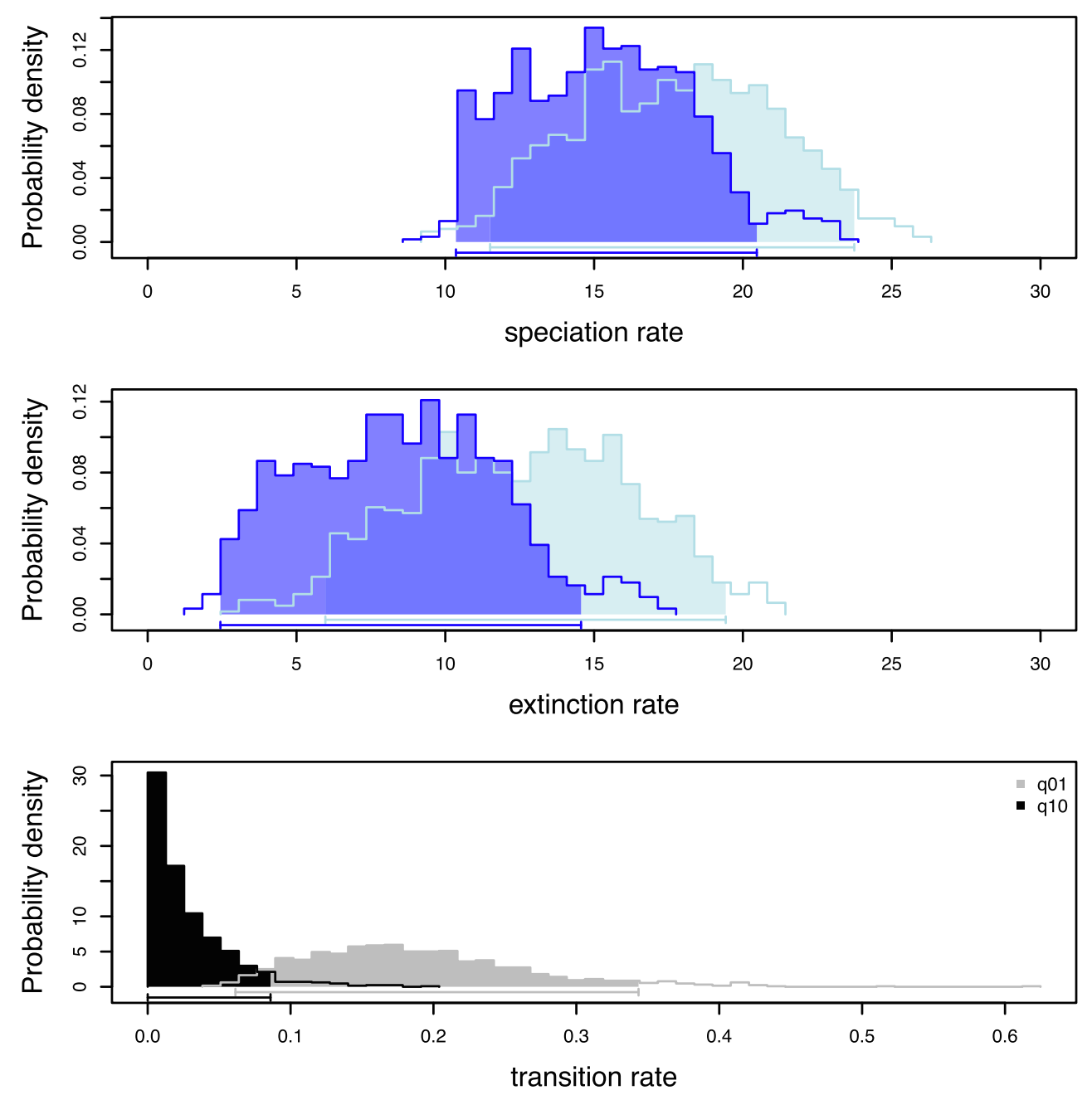

Fig. 4. Parameter estimates from BiSSE analyses. Panels show the density of the posterior probabilities of speciation and extinction rates (in units of substitutions per site) for anascan (light blue) versus ascophoran (blue), estimated from the global ML tree (see Supplementary Fig. S6 for Bayesian interpretation). Transition rates are also shown, where the transition from ascophoran to anascan is skewed towards zero, supporting the ancestral state reconstruction analyses. (For interpretation of the references to colour in this figure legend, the reader is referred to the web version of this article.) independently from the rest of incubating cheilostomes (Ostrovsky, 2013 , 2020). Our tree now corroborates this hypothesis with full bootstrap and posterior probability support. In addition, our analysis resurrects Calpensiidae (Canu and Bassler, 1923), as sister clade of Steginoporellidae, suggesting that Calpensia also broods its embryos in an internal sac as does Steginoporella (Ostrovsky, 2013), and supports the hypothesis of multiple independent evolution of internal brooding (e.g. in Chaperiidae, Inversiulidae, Watersiporidae, Cryptosulidae, Urceoliporidae) (e.g. Ostrovsky et al., 2006; Ostrovsky et al., 2009b) and placentation (e.g. in Bugulidae + Beaniidae, Catenicellidae, Watersiporidae, Urceoliporidae, and Celleporella hyalina) (e.g. Ostrovsky et al., 2009a; Ostrovsky et al. 2016).

A closely positioned clade formed by Monoporella (Monoporellidae) and Macropora (Macroporidae) shares the presence of large ooecia (Fig. 1C), exceptionally able to incubate several embryos at the same time, that evolved from basally articulated spines or costae (e.g. Ostrovsky, 2013) (but see next paragraph). The fully supported Arachnopusiidae (Arachnopusia) + Foveolariidae (Foveolaria and Odontionella) relationship is not indicated in present classification schemes (Bock, 2020), as species of Arachnopusia have an ascophoran state (Fig. 1F), while the Foveolariidae has an anascan state. However, we note that not only is the arachnopusiid frontal shield a straightforward structure to form (unlike other ascophoran structures), but some species in Arachnopusiidae (e.g. A. gigantea) are anascan-like, where the frontal shield is practically non-existent (Hayward, 1995).

\subsection{A need for even broader taxon sampling to fill gaps}

Our ML (Fig. 2, Supplementary Fig. S3) and Bayesian (Supplementary Fig. S4) trees are largely in agreement with only one clade demonstrating incongruence. This is the fully supported clade comprising Valdemunitella (currently Calloporidae), Figularia (currently Cribrilinidae) and Euthyroides (currently Euthyroididae). Based only on morphology, we might have hypothesized that the Valdemunitella clade (based on 4 species represented by 6 colonies) is closely associated with other representatives of the family Calloporidae (e.g. Crassimarginatella or Callopora), but neither of our trees inferred this position. Rather, our ML tree places this clade (including Figularia and Euthyroides, both currently belonging to other families) in a position close to Monoporellidae and Macroporidae (see paragraph above) and our Bayesian tree places it in a more derived position. However, note that nodes subtending this clade in both trees are poorly supported. Rather than speculating on evolutionary and/or morphological arguments for either or both of these placements, we argue this indicates that there are many crucial unsampled taxa that would potentially allow a more robust placement of this clade, such as other cribrilinids in addition to Figularia and other calloporids such as Cauloramphus which, similarly to Valdemunitella, has spines encircling the frontal uncalcified membrane, forming a costate shield in some species (Dick et al., 2011). In the event, Valdemunitella, Figularia and Euthyroides are morphologically united, not by a costate shield, but by identical bilobate ooecia with a median suture (e.g. Ostrovsky, 2013), and the presence of vicarious avicularia in most of their species. 


\subsection{The evolution of the cheilostome frontal-shield}

Historical studies of cheilostome body-wall development and morphology led to the conclusion that ascophoran frontal shields were phylogenetically informative (Banta, 1970; Gordon and Voigt, 1996; Sandberg, 1977). Our results substantiate the observation that characters considered to have deep phylogenetic information such as frontal shields are more evolutionarily labile than previously thought, and sometimes may even be convergent rather than homologous traits (Knight et al., 2011; Orr et al., 2019a). It has already been suggested, for instance, that anascan and ascophoran states, respectively regarded as stemward and crownward, have evolved more than once (Dick et al., 2009; Gordon, 2000; Waeschenbach et al., 2012). We show here that the anascan state is basal in the cheilostome tree and that the change from an anascan to ascophoran state has occurred multiple times independently (seven times in Fig. 3), hence likely more times in the history of cheilostome evolution, given our taxon sampling, which is far from complete. It is also striking that an ascophoran-state never reverts back to the anascan-state, suggesting that it is evolutionarily unproblematic to evolve a more complex calcified skeleton, but that once this structure is in place, it has not been lost again (Fig. 3). This is the "reverse" of what is the modern view of Dollo's law (Simpson 1953) where complex structures cannot be re-evolved (e.g. Collin and Miglietta 2008), where the morphological apparently "simpler" state (anascan) is not "gained" by the loss of the "complex" state (ascophoran). This could be due to genetic or developmental constraints (Smith et al., 1985), and/or because the advantages conferred by a calcified frontal shield vastly outweighs its disadvantages. Testing a classic idea that morphological complexity may predict diversification rates (Schopf et al., 1975), we found that the (potentially) more morphologically complex ascophorangrade cheilostomes do not have distinguishable speciation and extinction rates compared with anascan-grade ones.

The frontal shield clearly contains phylogenetic information, but more research is needed to understand when it is informative, and why. As a further example, frontal shields produced by different developmental processes (e.g., lepralioid or umbonuloid (Hayward and Ryland, 1999; Martha et al., 2020; Taylor, 2020)) leave such distinct morphological tell-tale signs that it was commonly assumed that members within families constituted only a single type of frontal shield development. Our tree, however, places ascophoran taxa with lepralioid frontal shields (e.g., Powellitheca/Cyclicopora; Celleporina, Galeopsis, Osthimosia) and umbonuloid ones (Exochella; Celleporaria) in the same clades (Fig. 2), as already shown to a lesser extent in earlier extensive studies (Dick et al., 2009; Orr et al., 2019a; Waeschenbach et al., 2012). Yet, at the more derived part of our inferred tree, the structure of the frontal shield seems to be more phylogenetically informative than seemingly distinct features such as the lyrula (Berning et al., 2014). This is an anvilshaped tooth-like structure projecting from the orifice that functions in water compensation. Specifically, the clade containing Parasmittina to Hemismittoidea (containing four and three genera of the families Smittinidae and Bitectiporidae respectively) has a non-pseudoporous umbonuloid frontal shield (Gordon, 2000), while the next one containing Schizosmittina to Bitectipora (containing two smittinid and two bitectiporid genera) has a pseudoporous lepralioid shield. The presence of a lyrula seems haphazard among these genera, where those in the Smittinidae have lyrula and those in the Bitectiporidae have a sinus (Fig. 1J, K). Our tree suggests new ways of partitioning some of the families and genera of Smittinoidea, which unexpectedly also includes the genera Porella (Bryocryptellidae) and Oshurkovia (Umbonulidae). To summarize, it is clear that a much more thorough and systematic investigation of the development and evolution of frontal shields, and greater taxonomic sampling, is necessary for a deeper understanding of ascophoran cheilostomes.

\subsection{Molecules suggest morphological hypotheses and pinpoint research needs}

Another example of traits thought to be phylogenetically related and hence informative is the sinus versus the ascopore, pertaining to the ascophoran plumbing system. Because Microporella, Fenestrulina and Calloporina all have ascopores, they were historically united in the Microporellidae. A previous molecular study has clearly shown that Fenestrulina does not belong in the same clade as Microporella (Orr et al., 2019b). Here, we give molecular support to the hypothesis that Calloporina is not a microporellid and further suggest that Chiastosella (having a sinus, currently belonging to the Escharinidae; Fig. $1 \mathrm{H}$ ) and Calloporina (having a slit-like ascopore; Fig. 1I) belong in the same clade, a relationship supported also by their shared distinctive ooecia (Brown, 1954; Cook et al., 2018). Supporting the long-held hypothesis that an ascopore should evolve by the cutting-off of a sinus, Chiastosella should be basalwards of Calloporina (Cook et al., 2018, p. 218). This is supported by our tree, which also suggests that Chiastosella may be paraphyletic with respect to Calloporina.

In multiple cases, taxa that are considered unique or unusual have placed in phylogenetic positions that suggest hypotheses of their evolutionary relationships based on morphology. For instance, Rhabdozoum, currently placed in its own family because of its highly distinctive morphology, is basal to Candidae, suggesting that they are closely related and that Candidae sensu stricto may have been derived from a Rhabdozoum-like ancestor. In fact, the initial zooid of the colony (ancestrula) of Rhabdozoum resembles those in some Scrupocellaria species and several of its mature zooidal features such as its ooecia, frontal avicularia and spines are reminiscent of species of Amastigia and Menipea (all Candidae s.s.). Margaretta, another rather distinct genus, is in a family with only one other monospecific genus (Tubucella). Here, Margaretta is inferred to be basal to Catenicellidae, suggesting that Catenicellidae s.s. may have been derived from a Margaretta-like ancestor, although it has always been thought that catenicellids are derived from cribrimorphs (Gordon, 2000; Gordon and Braga, 1994). Much research is required to unravel the mystery of this grouping, given that they are both so distinctive, sharing apparently only rhizoids, rootlets fixing the colony to the substrate which have independently evolved multiple times in all major orders of marine bryozoans (Schack et al., 2019). Note that we infer two distinct clades of Catenicellidae, one represented by Catenicella and Cornuticella, which are vittate (frontal pore chambers are long and narrow) and the second including Orthoscuticella and Pterocella, which are foraminate (frontal shield has numerous windows in the gymnocyst; Fig. 1G). Yet another example is the erect and branching calwelliid Malakosaria whose zooidal features resemble Fenestrulina (Fenestrulinidae), the genus in which Malakosaria nests in our tree.

One taxonomically challenging family deserves special mention. The speciose Celleporidae, with at least 252 described living taxa globally, is mostly characterized by nodular/massive colonies as a result of rapid frontal budding (the building of zooids on top of existing ones). As a consequence, autozooids are somewhat irregularly disposed and difficult to characterize morphologically. These genera are currently distinguished by the morphology of their ooecia (development of endooecium/tabula) and orifices (always sinuate but the sinus varies from a narrow slit to a broad and shallow concavity). Genus-level hypotheses based on these characters are problematic as indicated by our tree, in which Celleporina, Galeopsis (Fig. 1L) and Osthimosia are nonmonophyletic. Buffonellaria is excluded from the family and allied with Buffonellodidae, whereas Celleporaria, historically included in Celleporidae but subsequently split off because of its umbonuloid frontal shield (Harmer, 1957; Cook et al., 2018, p. 182), is reinstated.

\subsection{Lower-level cheilostome systematics are very robust}


that lower-level morphological hypotheses (i.e., species and genera) are very robust, supporting inferences based on common-garden experiments, to put forward the idea that "morphological species" are as good as "genetic species" in cheilostome bryozoans (Jackson and Cheetham, 1990). While Jackson and Cheetham experimented only with a handful of species, we now confirm their hard-earned insight implies that many more species and genera can be treated as distinct evolutionary lineages. This is an important result as many evolutionary and paleontological studies use morphospecies or even morpho-genera as the unit of analyses (Alroy, 2010; Heim et al., 2015). We also note that there are many New Zealand species in our tree that are yet undescribed (c. $20 \%$ of those newly sequenced here), indicating that continued exploration in the EEZ of New Zealand is crucial even for such a geographically wellcharacterized marine clade.

\section{Conclusions}

Our work shows that lower-level taxonomic sampling in phylogenetics is vital for understanding higher-level systematics, especially in an understudied group like cheilostome bryozoans. While we have contributed a substantial number of sequences from diverse species, many more must be included for the phylogenetic inferences and reliable systematic groupings for cheilostomes. By contributing molecular data and robustly supported phylogenetic inferences, we have supplied the basis for evolutionary (including phylogenetic) hypotheses that can be further examined. Once we are confident in the topology of at least parts of the cheilostome tree, we can start asking further questions on evolutionary processes.

\section{CRediT authorship contribution statement}

R.J.S. Orr: Data curation, Formal analysis, Investigation, Methodology, Project administration, Resources, Software, Validation, Visualization, Writing - original draft, Writing - review \& editing. E. Di Martino: Investigation, Methodology, Validation, Writing - original draft, Writing - review \& editing. D.P. Gordon: Validation, Writing original draft, Writing - review \& editing. M.H. Ramsfjell: Methodology, Writing - review \& editing. H.L. Mello: Resources, Writing - review \& editing. A.M. Smith: Resources, Writing - review \& editing. L.H. Liow: Conceptualization, Data curation, Formal analysis, Funding acquisition, Investigation, Methodology, Project administration, Resources, Validation, Visualization, Writing - original draft, Writing review \& editing.

\section{Declaration of Competing Interest}

The authors declare that they have no known competing financial interests or personal relationships that could have appeared to influence the work reported in this paper.

\section{Acknowledgements}

We thank Seabourne Rust for helping to sort and identify samples from the University of Otago, Sadie Mills for sending us samples from NIWA, Carolann Schack for her assistance during our Hawkes Bay field work and Kjetil L. Voje for identifying Steginoporella specimens. Specimens provided from the NIWA Invertebrate Collection were collected on numerous surveys including: Biodiversity survey of the western Ross Sea and Balleny Islands (TAN0402) undertaken by NIWA and financed by the former New Zealand Ministry of Fisheries (MFish); Oceans Survey 2020 Southern Colville Ridge (TAN1313) voyage, funded by Land Information New Zealand (LINZ) and GNS Science; Fisheries research trawl surveys conducted by NIWA and funded by Fisheries New Zealand (FNZ); Interdisciplinary New Zealand-Australian "MacRidge 2" research voyage (TAN0803), the biological component of which was part of NIWA's research project "Seamounts: their importance to fisheries and marine ecosystems" funded by the New Zealand Foundation for Research, Science and Technology (FRST) and CSIRO's Division of Marine and Atmospheric Research project "Biodiversity Voyages of Discovery" funded by the CSIRO Wealth from Oceans Flagship; Kerry Walton, University of Otago; Seamounts project (TAN0905) undertaken by NIWA and funded by FRST, with complementary funding from MFish; Scientific Observer Program funded by FNZ; Biogenic Habitats on the Continental Shelf project (voyages TAN1105 \& TAN1108), funded by New Zealand Ministry for Primary Industry (MPI), FRST, NIWA and LINZ; Ocean Survey 20/20 Bay of Islands Coastal Biodiversity, Sediment and Seabed Habitat Project (TAN0906, KAH0907), funded and owned by LINZ; Ocean Survey 20/20 Mapping the Mineral Resources of the Kermadec Arc Project (TAN1104), funded by LINZ, GNS, NIWA and Woods Hole Oceanographic Institution; Oceans Survey 2020 Reinga (TAN1312) voyage, funded by LINZ and New Zealand Petroleum \& Minerals; Impact of resource use on vulnerable deep-sea communities project (TAN1503), funded by the Ministry of Business, Innovation \& Employment (MBIE) with support from MPI; Joint Japan-Tonga Trench leg of the Quelle 2013 Expedition (YK13-10), funded by JAMSTEC and supported by NIWA; Food-web dynamics of New Zealand marine ecosystems supported by the New Zealand government under "Coasts \& Oceans" core funding from MBIE. We thank Lisbeth Thorsbek for help in the DNA isolation lab and the Norwegian Sequencing Centre (NSC) for library prep and sequencing and acknowledge Saga and Abel highperformance computing server time. This project has received funding from the European Research Council (ERC) under the European Union's Horizon 2020 research and innovation programme (grant agreement No 724324 to L.H. Liow)

\section{Appendix A. Supplementary data}

Supplementary data to this article can be found online at https://doi. org/10.1016/j.ympev.2021.107172.

\section{References}

Alroy, J., 2010. The shifting balance of diversity among major marine animal groups. Science 329 (5996), 1191-1194.

Altschul, S.F., Gish, W., Miller, W., Myers, E.W., Lipman, D.J., 1990. Basic local alignment search tool. J. Mol. Biol. 215 (3), 403-410.

Andrews, S., 2010. FastQC: A quality control tool for high throughput sequence data [Online]. Available online at: http://www.bioinformatics.babraham.ac.uk/project s/fastqc/.

Arrigoni, R., Vacherie, B., Benzoni, F., Stefani, F., Karsenti, E., Jaillon, O., Not, F., Nunes, F., Payri, C., Wincker, P., Barbe, V., 2017. A new sequence data set of SSU rRNA gene for Scleractinia and its phylogenetic and ecological applications. Mol. Ecol. Resour. 17 (5), 1054-1071.

Bankevich, A., Nurk, S., Antipov, D., Gurevich, A.A., Dvorkin, M., Kulikov, A.S., Lesin, V, M., Nikolenko, S.I., Pham, S., Prjibelski, A.D., Pyshkin, A.V., Sirotkin, A.V., Vyahhi, N., Tesler, G., Alekseyev, M.A., Pevzner, P.A., 2012. SPAdes: a new genome assembly algorithm and its applications to single-cell sequencing. J. Comput. Biol. 19 (5), 455-477.

Banta, W.C., 1970. The body wall of cheilostome Bryozoa. III. The frontal wall of Watersipora arcuata Banta, with a revision of the Cryptocystidea. J. Morphol. 131 (1), 37-56.

Berning, B., Tilbrook, K.J., Ostrovsky, A.N., 2014. What, if anything, is a lyrula? Studi Trentini di Scienze Naturali 94, 21-28.

Bernt, M., Donath, A., Jühling, F., Externbrink, F., Florentz, C., Fritzsch, G., Pütz, J., Middendorf, M., Stadler, P.F., 2013. MITOS: Improved de novo metazoan mitochondrial genome annotation. Mol. Phylogenet. Evol. 69 (2), 313-319.

Bock, P.E., 2020. The Bryozoa Home Page. http://www.bryozoa.net/.

Bock, P.E., Gordon, D.P., 2013. Phylum Bryozoa Ehrenberg, 1831. Zootaxa 3703, 67-74.

Bradstock, M., Gordon, D.P., 1983. Coral-like bryozoan growths in Tasman Bay, and their protection to conserve commercial fish stocks. N. Z. J. Mar. Freshwater Res. 17 (2), 159-163.

Brown, D.A., 1952. The Tertiary Cheilostomatous Polyzoa of New Zealand. Trustees of the British Museum (Natural History), London.

Brown, D.A., 1954. A new species of polyzoan, and notes on taxonomy. Trans. Roy. Soc. New Zealand 81, 557-561.

Campbell, H., Mortimer, N., 2014. Zealandia: Our Continent Revealed. Penguin Group New Zealand, Limited.

Canu, F., Bassler, R.S., 1923. North American later Tertiary and Quaternary Bryozoa. United States Natl. Museum Bull. 125, 1-302.

Collin, R., Miglietta, M.P., 2008. Reversing opinions on Dollo's Law. Trends Ecol. Evol. 23 (11), 602-609. 
Cook, P.L., Bock, P.E., Hayward, P.J., Gordon, D.P., 2018. Bryozoa of Australia, 2. CSIRO Publishing, Melbourne.

de Vienne, D.M., Giraud, T., Martin, O.C., 2007. A congruence index for testing topological similarity between trees. Bioinformatics 23 (23), 3119-3124.

Dick, M.H., Lidgard, S., Gordon, D.P., Mawatari, S.F., 2009. The origin of ascophoran bryozoans was historically contingent but likely. Proc. Roy. Soc. B: Biol. Sci. 276 (1670), 3141-3148.

Dick, M.H., Mawatari, S.F., Sanner, JoAnn, Grischenko, A.V., 2011. Cribrimorph and other Cauloramphus species (Bryozoa: Cheilostomata) from the Northwestern Pacific. Zoolog. Sci. 28 (2), 134-147.

FitzJohn, R.G., 2012. Diversitree: comparative phylogenetic analyses of diversification in R. Methods Ecol. Evol. 3, 1084-1092.

Fuchs, J., Obst, M., Sundberg, P., 2009. The first comprehensive molecular phylogeny of Bryozoa (Ectoprocta) based on combined analyses of nuclear and mitochondrial genes. Mol. Phylogenet. Evol. 52 (1), 225-233.

Gordon, D.P., 1984. The marine fauna of New Zealand: Bryozoa, Gymnolaemata from the Kermadec Ridge. New Zealand Oceanographic Institute Memoir 91.

Gordon, D.P., 1986. The marine fauna of New Zealand: Bryozoa, Gymnolaemata (Ctenostomata and Cheilostomata Anasca) from the western South Island continental shelf and slope. New Zealand Oceanographic Institute Memoir 95.

Gordon, D.P., 1989. The marine fauna of New Zealand: Bryozoa : Gymnolaemata (Cheilostomida Ascophorina) from the western South Island continental shelf and slope. New Zealand Oceanographic Institute Memoir 97.

Gordon, D.P., 1989. The marine fauna of New Zealand: Bryozoa : Gymnolaemata (Cheilostomida Ascophorina) from the western South Island continental shelf and slope. New Zealand Oceanographic Institute Memoir 97.

Gordon, D.P., 1989. The marine fauna of New Zealand: Bryozoa : Gymnolaemata (Cheilostomida Ascophorina) from the western South Island continental shelf and slope. New Zealand Oceanographic Institute Memoir 97.

Gordon, D.P., Bock, P.E., Souto-Derungs, J., Reverter-Gil, O., 2019. A bryozoan tale of two continents: faunistic data for the recent Bryozoa of Greater Australia (Sahul) and Zealandia, with European comparisons. Australasian Palaeontol. Memoirs 52, 13-22.

Gordon, D.P., Braga, G., 1994. Bryozoa: Living and fossil species of the catenicellid subfamilies Ditaxiporinae Stach and Vasignyellidae nov. In: Crosnier, A. (Ed.), Résultats des Campagnes MUSORSTOM. Mémoires du Muséum National d'Histoire Naturelle 161, 55-85.

Gordon, D.P., Clark, A.G., Harper, J.F., 1987. Bryozoa. In: Pandian, T.J., Vernberg, F.J. (Eds.), Animal Energetics. Volume 2. Bivalvia through Reptilia. Academic Press, New York, pp. 173-199.

Gordon, D.P., Taylor, P.D., 2015. Bryozoa of the Early Eocene Tumaio Limestone, Chatham Island, New Zealand. J. Syst. Paleontol. 13 (12), 983-1070.

Gordon, D.P., Taylor, P.D., Bigey, F.P., 2009. Phylum Bryozoa - moss animals, sea mats, lace corals. In: Gordon, D.P. (Ed.), New Zealand Inventory of Biodiversity. Canterbury University Press, Christchurch, pp. 271-297.

Gordon, D.P., Voigt, E., 1996. The kenozooidal origin of the ascophorine hypostegal coelom and associated frontal shield. In: Gordon, D.P., Smith, A.M., Grant-Mackie, J A. (Eds.), Bryozoans in Space and Time. NIWA, Wellington, pp. 89-107.

Harmer, S.F., 1957. The Polyzoa of the Siboga Expedition, Part 4. Cheilostomata Ascophora II. Siboga Expedition Reports, pp. xv 641-1147, pls. 1142-1174.

Hayward, P.J., 1995. Antarctic Cheilostomatous Bryozoa. Oxford University Press.

Hayward, P.J., Ryland, J.S., 1999. Cheilostomatous Bryozoa Part 2. Hippothooidea Celleporoidea. British ascophoran bryozoans. Notes for the identification of British species. Synopses of the British Fauna, New Series 14.

Heath, T.A., Huelsenbeck, J.P., Stadler, T., 2014. The fossilized birth-death process for coherent calibration of divergence-time estimates. Proc. Natl. Acad. Sci. 111 (29), E2957-E2966.

Heim, N.A., Knope, M.L., Schaal, E.K., Wang, S.C., Payne, J.L., 2015. Cope's rule in the evolution of marine animals. Science 347 (6224), 867-870.

Huelsenbeck, J.P., Ronquist, F., 2001. MrBayes: Bayesian inference of phylogenetic trees. Bioinformatics 17 (8), 754-755.

Jackson, J.B.C., Cheetham, A.H., 1990. Evolutionary significance of morphospecies - a test with cheilostome Bryozoa. Science 248 (4955), 579-583.

Katoh, K., Standley, D.M., 2013. MAFFT Multiple equence Alignment Software Version 7: Improvements in performance and usability. Mol. Biol. Evol. 30, 772-780.

Knight, S., Gordon, D.P., Lavery, S.D., 2011. A multi-locus analysis of phylogenetic relationships within cheilostome bryozoans supports multiple origins of ascophoran frontal shields. Mol. Phylogenet. Evol. 61 (2), 351-362.

Kocot, K.M., Tassia, M.G., Halanych, K.M., Swalla, B.J., 2018. Phylogenomics offers resolution of major tunicate relationships. Mol. Phylogenet. Evol. 121, 166-173.

Krueger, F., 2015. TrimGalore. http://www.bioinformatics.babraham.ac.uk/projects/tri m_galore/.

Lagesen, K., Hallin, P., Rødland, E.A., Stærfeldt, H.-H., Rognes, T., Ussery, D.W., 2007. RNAmmer: consistent and rapid annotation of ribosomal RNA genes. Nucleic Acids Res. 35 (9), 3100-3108.

Lidgard, S., 2008. Predation on marine bryozoan colonies: taxa, traits and trophic groups. Mar. Ecol. Prog. Ser. 359, 117-131.

Maddison, W.P., Maddison, D.R., 2017. Mesquite: a modular system for evolutionary analysis. Version 3.1 http://mesquiteproject.org.

Maddison, W.P., Midford, P.E., Otto, S.P., Oakley, T., 2007. Estimating a binary character's effect on speciation and extinction. Syst. Biol. 56 (5), 701-710.

Martha, S., Vieira, L., Souto, J., Grischenko, A.V., Gordon, D.P., Ostrovsky, A.N., 2020. Gymnolaemata, Cheilostomata. In: Schwaha, T.F. (Ed.), Handbook of Zoology. Phylum Bryozoa, De Gruyter, Berlin, pp. 317-433.

Meredith, R.W., Janecka, J.E., Gatesy, J., Ryder, O.A., Fisher, C.A., Teeling, E.C., Goodbla, A., Eizirik, E., Simao, T.L.L., Stadler, T., Rabosky, D.L., Honeycutt, R.L.,
Flynn, J.J., Ingram, C.M., Steiner, C., Williams, T.L., Robinson, T.J., BurkHerrick, A., Westerman, M., Ayoub, N.A., Springer, M.S., Murphy, W.J., 2011. Impacts of the Cretaceous terrestrial revolution and KPg extinction on mammal diversification. Science 334 (6055), 521-524.

Nylander, J.A.A., 2010. catfasta2phyml. https://github.com/nylander/catfasta2phyml.

O'Hara, T.D., Hugall, A.F., Thuy, B., Stöhr, S., Martynov, A.V., 2017. Restructuring higher taxonomy using broad-scale phylogenomics: The living Ophiuroidea. Mol. Phylogenet. Evol. 107, 415-430.

Orr, R.J.S., Haugen, M.N., Berning, B., Bock, P.E., Cumming, R.L., Florence, W.K., Hirose, M., Di Martino, E., Ramsfjell, M.H., Sannum, M.M., Smith, A.M., Vieira, L.M., Waeschenbach, A., Liow, L.H., 2019a. A genome-skimmed phylogeny of a widespread bryozoan family, Adeonidae. BMC Evolution. Biol. 19, 235.

Orr, R.J.S., Sannum, M.M., Boessenkool, S., Di Martino, E., Gordon, D.P., Mello, H.L., Obst, M., Ramsfjell, M.H., Smith, A.M., Liow, L.H., 2020. A Molecular phylogeny of historical and contemporary specimens of an under-studied micro-invertebrate group. Ecol. Evol. 11 (1), 309-320.

Orr, R.J.S., Waeschenbach, A., Enevoldsen, E.L.G., Boeve, J.P., Haugen, M.N., Voje, K.L., Porter, J., Zágoršek, K., Smith, A.M., Gordon, D.P., Liow, L.H., 2019b. Bryozoan genera Fenestrulina and Microporella no longer confamilial; multi-gene phylogeny supports separation. Zool. J. Linn. Soc. 186 (1), 190-199.

Ostrovsky, A. (Ed.), 2013. Evolution of Sexual Reproduction in Marine Invertebrates. Springer Netherlands, Dordrecht.

Ostrovsky, A.N., 2020. Sexual reproduction in Bryozoa. In: Schwaha, T.F. (Ed.), Handbook of Zoology. Phylum Bryozoa, De Gruyter, Berlin, pp. 317-433.

Ostrovsky, A.N., Gordon, D.P., Lidgard, S., 2009a. Independent evolution of matrotrophy in the major classes of Bryozoa: transitions among reproductive patterns and their ecological background. Mar. Ecol. Prog. Ser. 378, 113-124.

Ostrovsky, A.N., Grischenko, A.V., Taylor, P.D., Bock, P., Mawatari, S.F., 2006. Comparative anatomical study of internal brooding in three anascan bryozoans (Cheilostomata) and its taxonomic and evolutionary implications. J. Morphol. 267 (6), 739-749.

Ostrovsky, A.N., Lidgard, S., Gordon, D.P., Schwaha, T., Genikhovich, G., Ereskovsky, A. V., 2016. Matrotrophy and placentation in invertebrates: a new paradigm. Biol. Rev. 91 (3), 673-711.

Ostrovsky, A.N., O’Dea, A., Rodríguez, F., 2009b. Comparative anatomy of internal incubational sacs in cupuladriid bryozoans and the evolution of brooding in freeliving cheilostomes. J. Morphol. 270 (12), 1413-1430.

Pagel, M., 1994. Detecting correlated evolution on phylogenies: a general method for the comparative analysis of discrete characters. Proc. R. Soc. Lond. B Biol. Sci. 255 $37-45$.

Pagès-Escolà, M., Costello, M.J., 2020. The biology, ecology and societal importance of marine bryozoa. In: Goldstein, M.I., DellaSala, D.A. (Eds.), Encyclopedia of the World's Biomes. Elsevier, Oxford, pp. 499-503.

Paradis, E., Schliep, K., 2018. ape 5.0: an environment for modern phylogenetics and evolutionary analyses in R. Bioinformatics $35,526-528$.

Pollock, D.D., Zwickl, D.J., McGuire, J.A., Hillis, D.M., Crandall, K., 2002. Increased taxon sampling is advantageous for phylogenetic inference. Syst. Biol. 51 (4), 664-671.

Prum, R.O., Berv, J.S., Dornburg, A., Field, D.J., Townsend, J.P., Lemmon, E.M., Lemmon, A.R., 2015. A comprehensive phylogeny of birds (Aves) using targeted next-generation DNA sequencing. Nature 526 (7574), 569-573.

Pyron, R.A., 2015. Post-molecular systematics and the future of phylogenetics. Trends Ecol. Evol. 30 (7), 384-389.

Rabosky, D.L., Goldberg, E.E., 2015. Model inadequacy and mistaken inferences of traitdependent speciation. Syst. Biol. 64 (2), 340-355.

Rust, S., Gordon, D., 2011. Plio-Pleistocene bryozoan faunas of the Wanganui Basin, New Zealand: stratigraphic distribution and diversity. N. Z. J. Geol. Geophys. 54 (2), 151-165.

Sandberg, P.A., 1977. Ultrastructure, mineralogy, and development of bryozoan skeletons. In: Woollacott, R.M., Zimmer, R.L. (Eds.), Biology of Bryozoans. Academic Press, New York.

Schack, C.R., Gordon, D.P., Ryan, K.G., 2019. Modularity is the mother of invention: a review of polymorphism in bryozoans. Biol. Rev. 94 (3), 773-809.

Schack, C.R., Gordon, D.P., Ryan, K.G., 2020. Community assembly in a modular organism: the impact of environmental filtering on bryozoan colony form and polymorphism. Ecology 101, e03106.

Schopf, T.J.M., Raup, D.M., Gould, S.J., Simberloff, D.S., 1975. Genomic versus morphologic rates of evolution: influence of morphologic complexity. Paleobiology 1 (1), 63-70.

Simpson, G.G., 1953. The Major Features of Evolution. Columbia University Press.

Smith, J.M., Burian, R., Kauffman, S., Alberch, P., Campbell, J., Goodwin, B., Lande, R., Raup, D., Wolpert, L., 1985. Developmental constraints and evolution: A perspective from the mountain lake conference on development and evolution. Q. Rev. Biol. 60 (3), 265-287.

Smith, S.A., Beaulieu, J.M., Donoghue, M.J., 2009. Mega-phylogeny approach for comparative biology: an alternative to supertree and supermatrix approaches. BMC Evol. Biol. 9 (1), 37. https://doi.org/10.1186/1471-2148-9-37.

Stamatakis, A., 2006. RAxML-VI-HPC: maximum likelihood-based phylogenetic analyses with thousands of taxa and mixed models. Bioinformatics 22 (21), 2688-2690.

Talavera, G., Castresana, J., 2007. Improvement of phylogenies after removing divergent and ambiguously aligned blocks from protein sequence alignments. System. Biol. 56, 564-577.

Tanabe, A.S., 2016. MrBayes5d. https://github.com/astanabe/mrbayes5d.

Taylor, P.D., 2020. Bryozoan Paleobiology. Wiley-Blackwell, Hoboken.

Taylor, P.D., Waeschenbach, A., 2015. Phylogeny and diversification of bryozoans. Palaeontology 58 (4), 585-599. 
Varga, T., Krizsán, K., Földi, C., Dima, B., Sánchez-García, M., Sánchez-Ramírez, S., Szöllősi, G.J., Szarkándi, J.G., Papp, V., Albert, L., Andreopoulos, W., Angelini, C., Antonín, V., Barry, K.W., Bougher, N.L., Buchanan, P., Buyck, B., Bense, V., Catcheside, P., Chovatia, M., Cooper, J., Dämon, W., Desjardin, D., Finy, P., Geml, J., Haridas, S., Hughes, K., Justo, A., Karasiński, D., Kautmanova, I., Kiss, B.,

Kocsubé, S., Kotiranta, H., LaButti, K.M., Lechner, B.E., Liimatainen, K., Lipzen, A., Lukács, Z., Mihaltcheva, S., Morgado, L.N., Niskanen, T., Noordeloos, M.E., Ohm, R. A., Ortiz-Santana, B., Ovrebo, C., Rácz, N., Riley, R., Savchenko, A., Shiryaev, A., Soop, K., Spirin, V., Szebenyi, C., Tomšovský, M., Tulloss, R.E., Uehling, J., Grigoriev, I.V., Vágvölgyi, C., Papp, T., Martin, F.M., Miettinen, O., Hibbett, D.S., Nagy, L.G., 2019. Megaphylogeny resolves global patterns of mushroom evolution. Nat. Ecol. Evol. 3 (4), 668-678.
Waeschenbach, A., Taylor, P.D., Littlewood, D.T.J., 2012. A molecular phylogeny of bryozoans. Mol. Phylogenet. Evol. 62 (2), 718-735.

Wood, A.C.L., Probert, P.K., Rowden, A.A., Smith, A.M., 2012. Complex habitat generated by marine bryozoans: a review of its distribution, structure, diversity, threats and conservation. Aquat. Conserv. Mar. Freshwater Ecosyst. 22 (4), 547-563.

Zanne, A.E., Tank, D.C., Cornwell, W.K., Eastman, J.M., Smith, S.A., FitzJohn, R.G., McGlinn, D.J., O'Meara, B.C., Moles, A.T., Reich, P.B., Royer, D.L., Soltis, D.E., Stevens, P.F., Westoby, M., Wright, I.J., Aarssen, L., Bertin, R.I., Calaminus, A., Govaerts, R., Hemmings, F., Leishman, M.R., Oleksyn, J., Soltis, P.S., Swenson, N.G., Warman, L., Beaulieu, J.M., 2014. Three keys to the radiation of angiosperms into freezing environments. Nature 506 (7486), 89-92. 